\title{
CARACTERIZAÇÃO FÍSICO-QUÍMICA, BIOQUÍMICA E FUNCIONAL DA JABUTICABA ARMAZENADA SOB DIFERENTES TEMPERATURAS ${ }^{1}$
}

\author{
ROGÉRIO LOPES VIEITES ${ }^{2}$, ÉRICA REGINA DAIUTO 3 , MARIA ROSA DE MORAES ${ }^{4}$, \\ LEANDRO CAMARGO NEVES ${ }^{5}$, LÍDIA RAQUEL DE CARVALHO ${ }^{6}$
}

RESUMO-O presente trabalho teve como objetivo avaliar a qualidade pós-colheita de jabuticabas submetidas a diferentes temperaturas de armazenamento refrigerado (AR). Após a colheita, os frutos fisiologicamente maduros foram acondicionados em bandejas de poliestireno expandido (EPS), revestidas por filme plástico de polietileno de baixa densidade (PEBD) e armazenados sob refrigeração a $0 ; 3 ; 6 ; 9$ e $12 \pm 1^{\circ} \mathrm{C}$ e U.R. $87 \pm$ $2 \%$, sendo avaliados a cada 5 dias. Os frutos foram avaliados quanto à perda de massa, atividade respiratória, pH, acidez titulável, sólidos solúveis, ácido ascórbico, textura, pectina total e solúvel, atividade da enzima polifenoloxidase (PFO), compostos fenólicos e atividade antioxidante. Para frutos refrigerados a 9 e $12^{\circ} \mathrm{C}$, o pico respiratório atrasou em relação aos demais tratamentos, além de apresentarem as menores taxas respiratórias. O teor de sólidos solúveis aumentou com o tempo de armazenamento para todas as temperaturas, contudo, em 9 e $12^{\circ} \mathrm{C}$, esse aumento foi em menor proporção. A firmeza e o teor de ácido ascórbico também foram superiores nos frutos armazenados a 9 e $12^{\circ} \mathrm{C}$, enquanto os contéudos de pectina solúvel foram menores. Observou-se a diminuição da atividade da enzima PFO ao longo dos 30 dias do AR, independentemente da temperatura utilizada; entretanto, os menores valores foram encontrados nos frutos mantidos a 9 e $12^{\circ} \mathrm{C}$. Os frutos armazenados a $12^{\circ} \mathrm{C}$ apresentaram os maiores conteúdos de compostos fenólicos totais e a maior atividade antioxidante ao final do experimento. Nesse sentido, a temperatura de $12^{\circ} \mathrm{C}$ foi a mais efetiva na manutenção da qualidade pós-colheita das jabuticabas.

Termos para indexação: Myrciaria jaboticaba (Vell.) Berg, conservação, componentes funcionais.

\section{PHYSIOCHEMICAL, BIOCHEMISTRY AND FUNCTIONAL CHARACTERIZATION OF JABUTICABA STORED UNDER DIFFERENT TEMPERATURES}

\begin{abstract}
The present study aimed to measure the postharvest quality, the total phenolic compounds and antioxidant capacity of the jabuticaba fruits under a modified atmosphere at different temperatures of cold storage. After the fruits were harvested in the mature green stage, they were packed in expanded polystyrene (EPS) trays, covered by low densidy polyethylene (LDPE) plastic film and, stored at 0, 3, 6, 9 and $12 \pm 1{ }^{\circ} \mathrm{C}$ and $\mathrm{RH}$ of $87 \pm 2 \%$, being evaluated every 5 days. Fruit were evaluated for weight loss, respiratory rate, $\mathrm{pH}$, titrable acidity, soluble solids content, ascorbic acid content, texture, total and soluble pectin and polyphenoloxidase activity, phenolics composition and antioxidant capacity. For the fruits stored at 9 and $12^{\circ} \mathrm{C}$ the respiratory peak was delayed when compared to other fruits stored at low temperatures, and the respiration rate was lower. The soluble solid contents increased with storage time at all temperatures, but at 9 and $12^{\circ} \mathrm{C}$ the increase was proportionally smaller. The texture and ascorbic acid contents were also higher in fruits stored at 9 and $12^{\circ} \mathrm{C}$, and they showed the lowest levels of soluble pectin. The polyphenoloxidase activity decrease during the 30 days of cold storage, independent of the temperature, but the lowest values were found in the fruit stored at 9 and $12^{\circ} \mathrm{C}$. With respect to the total phenolic compounds and antioxidant activity, the fruits stored at $12^{\circ} \mathrm{C}$ showed the best scores after 30 days of cold storage. In this sense, the temperature of $12^{\circ} \mathrm{C}$ was more effective in maintaining the postharvest quality of the jabuticabas.
\end{abstract}

Index terms: Myrciaria jaboticaba (Vell.) Berg, conservation, functional compounds.

\footnotetext{
${ }^{1}$ (Trabalho 149-10). Recebido em: 11-06-2010. Aceito para publicação em: 04-02-2011. Projeto Financiado pela FAPESP; ${ }^{2}$ Docente Departamentos de Gestão e Tecnologia Agroindustrial da Faculdade de Ciências Agronômicas da UNESP-Botucatu, E-mail: vieites@fca.unesp.br

${ }^{3}$ Pós doutoranda da Faculdade de Ciências Agronômicas da UNESP-Botucatu, E-mail: erdaiuto@uol.com.br

${ }^{4}$ Aluna de iniciação científica, E-mail: mrmoraes@fca.unesp.br

${ }^{5}$ Docente Departamento de Fitotecnia da Universidade Federal de Roraima, E-mail: rapelbtu@hotmail.com

${ }^{6}$ Docente Departamento de Bioestatística- IB/UNESP-Botucatu, E-mail: lidiarc@ibb.unesp.br
} 


\section{INTRODUÇÃO}

A jabuticaba é nativa do Brasil e, dentre as espécies comerciais atualmente conhecidas, destacam-se a Myrciaria cauliflora (Mart.) O. Berg. e a Myrciaria jaboticaba (Vell.) Berg.. A cultivar Sabará, da espécie M. jaboticaba (Vell.) Berg., é a mais difundida no Brasil, cujos frutos são apropriados tanto para a industrialização como para consumo in natura (DONADIO, 2000). O potencial econômico de comercialização desse fruto é grande, em função das características sensoriais para consumo in natura, além de ser utilizado na fabricação de licores e geleias (MAGALHÃES et al., 1996).

Os frutos são altamente perecíveis, o período de comercialização após a colheita é curto devido à rápida alteração da aparência, decorrente da intensa perda de umidade, deterioração e fermentação da polpa, observadas em apenas dois a três dias após a colheita. $\mathrm{O}$ uso de tecnologias em pós-colheita que visem à diminuição do metabolismo dos frutos, objetivando a redução da aceleração do amadurecimento e, consequentemente, o prolongamento da conservação, é fundamental para o sucesso comercial das jabuticabas (CORRÊA et al., 2007).

O AR é efetivo por retardar os processos metabólicos envolvidos na ação das enzimas degradativas e oxidativas e por reduzir a respiração e a produção do etileno, sendo a eficiência de controle maior quanto mais rápido se processa o resfriamento após a colheita. Segundo Martins et al. (2007), o AR consiste no principal meio de conservação dos vegetais, podendo ser associado a outros tratamentos em pós-colheita, como a atmosfera modificada (AM).

Os consumidores estão cada vez mais exigentes em relação aos alimentos e produtos, procurando por aqueles mais nutritivos, seguros e que preservem a saúde (DURIGAN, 2004). Essa é uma tendência mundial que tem reflexo na produção de alimentos de qualidade. Durante o armazenamento podem ocorrer alterações na aparência, sabor, textura e cor, que se refletem na qualidade nutritiva do produto in natu$r a$, pré-processado e processado. No entanto, hoje existe um grande apelo pelas qualidades nutritivas dos alimentos como forma de prevenção de doenças. Nessa categoria, incluem antioxidantes presentes nos alimentos, como a vitamina $\mathrm{C}, \mathrm{E}$ e compostos fenólicos.

Pesquisas com jabuticabas têm sido realizadas objetivando avaliar o efeito da AM na qualidade pós-colheita durante o AR. Esses trabalhos visam a prolongar o período de vida útil dos frutos (BRUNINI et al., 2004), tanto para consumo in natura como para o processamento (MACHADO et al., 2007).
No entanto, esses trabalhos ainda não abordam a manutenção da qualidade funcional do fruto, bem como suas caracteristicas bioquímicas.

Assim, a execução deste trabalho teve por objetivo verificar a temperatura de AR mais apropriada na conservação pós-colheita de frutos de jabuticaba, visando à manutenção da qualidade funcional e bioquímica dos frutos.

\section{MATERIAL E MÉTODOS}

As jabuticabas da cultivar Sabará, espécie M. jaboticaba (Vell.), foram adquiridas em pomar comercial na região de São Carlos-SP. A cidade está situada a 830 metros de altitude em relação ao nível do mar, a $22^{\circ} 0$ ' $10^{\prime \prime}$ latitude S e $47^{\circ} 53^{\prime} 38^{\prime \prime}$ longitude W. O clima da região é o tropical de altitude, com verões chuvosos e invernos secos, caracterizando 6 meses quentes e úmidos e 6 meses frios e secos. A amplitude térmica, em média, é de $10,7^{\circ} \mathrm{C}$ (máxima de $26,9^{\circ} \mathrm{C}$ e mínima de $16,2^{\circ} \mathrm{C}$ ). A precipitação pluviométrica está em torno de $1.500 \mathrm{~mm}$ anuais.

As análises laboratoriais foram realizadas nos Laboratórios de Pós-Colheita de Frutos e Hortaliças da Universidade Estadual Paulista e de Tecnologia de Alimentos da Universidade Federal de Roraima, por meio de amostras liofilizadas e congeladas a $-80^{\circ} \mathrm{C}$.

Os frutos colhidos 30 dias após o florescimento (DAF), segundo recomendação dos produtores da região, foram transportados até o laboratório em caixas de isopor refrigeradas de 16 litros, com o auxílio de gelo seco, que manteve a temperatura em aproximadamente $16^{\circ} \mathrm{C}$, por 3 horas. Posteriormente, os frutos foram selecionados pela ausência de defeitos visuais, sendo higienizados com sabão neutro e hipoclorito de sódio a 200 ppm. O enxágue e a secagem dos frutos foram feitos em bandejas perfuradas expostas ao ar atmosférico $\left(24 \pm 2,5^{\circ} \mathrm{C}\right.$ e $87 \pm 2 \%$ de U.R.). Após a higienização, os frutos foram pré-resfriados em câmara frigorífica, por 12 horas, a $10 \pm 0,5^{\circ} \mathrm{C}$, visando ao pré-resfriamento.

A partir daí, para a constituição dos tratamentos, 20 frutos foram acondicionados em embalagens de poliestireno expandido $(0,25 \times 0,22 \mathrm{~m}) \mathrm{e}$ revestidas por filme plástico de polietileno de baixa densidade (PEBD), de $0,006 \mathrm{~mm}$ de espessura $\left(\mathrm{TPO}_{2}\right.$ em $\mathrm{cm}^{3} \cdot \mathrm{m}^{-2} \cdot \mathrm{dia}^{-1}$, a $25^{\circ} \mathrm{C}$ e $1 \mathrm{~atm}$, de 18,1 e $\mathrm{TPCO}_{2}$ $\mathrm{em} \mathrm{cm}{ }^{3} \cdot \mathrm{m}^{-2} \cdot \mathrm{dia}^{-1}$ a $25^{\circ} \mathrm{C}$ e $1 \mathrm{~atm}$, de 75,6 , área de permeabilidade de $790 \mathrm{~cm}^{2}$ ). Para determinar a melhor temperatura de refrigeração da jabuticaba sob AM, foram realizados 5 tratamentos, nos quais os frutos foram acondicionados em câmara frigorífica, em temperaturas de $0 ; 3 ; 6 ; 9$ e $12 \pm 1^{\circ} \mathrm{C}$ e $87 \pm 2 \%$ de U.R. As análises foram realizadas a cada 5 dias, sempre 
12 horas após a retirada dos frutos do AR, durante 30 dias. Nesse período, os frutos eram mantidos a 24 $\pm 2,5^{\circ} \mathrm{C}$ e $87 \pm 2 \%$ de U.R., visando ao período de comercialização simulada.

Foram realizadas as seguintes análises: perda de massa fresca, pela pesagem das embalagens em balança analítica, considerando a massa inicial de cada amostra, com os resultados expressos em percentagem.

A respiração foi determinada pela liberação de $\mathrm{CO}_{2}$ em cada embalagem, de acordo com metodologia adaptada de Bleinroth et al. (1976), utilizando-se para isso de solução de hidróxido de bário saturado e solução de hidróxido de potássio $0,1 \mathrm{~N}$. Para tanto, foi utilizada a seguinte fórmula: $\mathrm{TCO}_{2}=2,2(\mathrm{Vo}-\mathrm{V} 1)$. 10/P.T. Em que: $\mathrm{T} \mathrm{CO}_{2}=$ taxa de respiração $(\mathrm{mL}$ de $\left.\mathrm{CO}_{2} . \mathrm{Kg}^{-1} \cdot \mathrm{h}^{-1}\right)$; Vo = volume gasto de $\mathrm{HCl}$ para titulação de hidróxido de potássio - padrão antes da absorção de $\mathrm{CO}_{2}(\mathrm{~mL}) ; \mathrm{V} 1$ = volume gasto de ácido clorídrico $(\mathrm{HCl})$ para titulação de hidróxido de potássio após a absorção de $\mathrm{CO}_{2}$ da respiração $(\mathrm{mL}) ; \mathrm{P}$ $=$ massa dos frutos; $\mathrm{T}=$ tempo da respiração; $2,2=$ inerente ao equivalente de $\mathrm{CO}_{2}(44 / 2)$, multiplicado pela concentração do ácido clorídrico; $10=$ ajuste para o total de hidróxido de potássio utilizado.

O teor de sólidos solúveis foi medido, em leitura refratométrica em ${ }^{\circ} \mathrm{Brix}$, a $20^{\circ} \mathrm{C}$, com refratômetro digital, conforme metodologia do ZENEBON; PASCUET (2008).

O conteúdo de acidez titulável foi determinada pela titulação de $10 \mathrm{~g}$ de polpa homogeneizada e diluída para $90 \mathrm{ml}$ de água destilada, com solução padronizada de $\mathrm{NaOH}$ a $0,1 \mathrm{~N}$, usando a fenolftaleína ( $\mathrm{pH} 8,1 \pm 1$ ) como indicador e resultados expressos em $\mathrm{g}$ de ácido cítrico. $100 \mathrm{~g}^{-1}$ de polpa, conforme recomendação do ZENEBON; PASCUET (2008).

$\mathrm{O}$ teor de ácido ascórbico foi quantificado pelo método colorimétrico com 2,4-dinitrofenilidrazina, utilizando-se de $5 \mathrm{~g}$ de amostra, segundo IAL (2008), e os resultados, expressos em mg de ácido ascórbico. $100^{-1} \mathrm{~g}$ de polpa.

A avaliação da firmeza foi feita utilizando-se de texturômetro, com a distância de penetração de $20 \mathrm{~mm}$, velocidade de $2,0 \mathrm{~mm} / \mathrm{seg}$. e ponta de prova TA 9/1000, e os resultados foram apresentados em gramas.força ${ }^{1}$. Foram realizadas 5 leituras em cada uma das 3 repetições, em todos os tratamentos.

O conteúdo de pectina total e solúvel foi obtido segundo técnica preconizada por McCready e McComb (1952) e analisadas; e os resultados, expressos em percentagem pelo método modificado por Blumenkrantz e Asboe-Hansen (1973).

A atividade da enzima polifenoloxidase (PFO) foi determinada pelo método de Cano et al. (1997); e os resultados, expressos em $\Delta \mathrm{A}_{395} \min ^{-1} \mathrm{~g}^{-1} \mathrm{MF}$.

O conteúdo de compostos fenólicos totais foram determinados pelo método espectrofotométrico de Folin-Ciocalteau, descrito por Singleton et al. (1999), utilizando ácido gálico como padrão; e os resultados, expressos em mg GAE.100 $\mathrm{g}^{-1}$ de peso seco.

A capacidade antioxidante das amostras liofilizadas foi avaliada por dois métodos analíticos: ORAC (Oxygen radical absorbance capacity) e $\mathrm{DPPH} \bullet$ (2,2-diphenyl-1-picrylhydrazyl):

a) O método ORAC foi descrito por Ou et al. (2001) e adaptado por Huang et al. (2002) para uso em microplacas usando fluoresceína. A quantificação da atividade antioxidante foi baseada no cálculo da área sob a curva de decaimento da fluorescência, como proposto por Prior et al. (2003). Os resultados foram expressos em $\mu$ mol Eq Trolox. ${ }^{-1}$ de amostra seca.

b) O método DPPH• foi realizado segundo Blois (1958) e Brand-Willians et al. (1995), no qual o decaimento da absorbância das amostras (Aam) foi correlacionado ao decaimento da absorbância do controle (Ac), resultando na porcentagem de sequestro de radicais livres (\% SRL), que foi expressa pela seguinte equação: \% SRL $=((\mathrm{AC}-$ Aam) $\left.\times A^{-1}\right) \times 100$. Os resultados foram expressos em $\mu$ mol Eq Trolox. $g^{-1}$ de amostra seca.

Após a análise exploratória dos dados, constatou-se que os mesmos seguem distribuição normal, os erros são independentes e apresentam homocedasticidade. Os dados foram então submetidos à análise de regressão linear ou polinomial de segundo grau, conforme o caso.

\section{RESULTADOS E DISCUSSÃO}

\section{Perda de massa fresca}

Os resultados para análise de perda de massa fresca, representada por uma regressão linear única para os 5 tratamentos (Figura 1) dos frutos foram crescentes, independentemente da temperatura utilizada para o AR. Contudo, além de não se observar diferença significativa entre os tratamentos, também pôde constatar-se que essas perdas não foram capazes de causar notáveis murchamentos e/ ou enrugamentos nos frutos que pudessem comprometer sua qualidade.

Vale ressaltar que, para a maioria dos produtos hortícolas frescos, a máxima perda de massa fresca tolerada para o não aparecimento de murcha e/ou enrugamento da superfície oscila entre 5 e $10 \%$ (FINGER; VIEIRA, 2002). Nesta pesquisa, a umidade perdida foi, em média, $2 \%$ 
da massa inicial de cada amostra. Portanto, assim como relatado por Brunini et al. (2004), observou-se que as perdas de massa fresca das jabuticabas refrigeradas em temperaturas de 0 a $12^{\circ} \mathrm{C}$ e revestidas com filmes plásticos de PEBD estavam dentro do intervalo aceitável citado na literatura. Dados esses concordantes com Neves et al. (2008a), onde é afirmado que um dos fatores mais preponderantes quanto à eficiência da $\mathrm{AM}$ na preservação da qualidade pós-colheita é o controle das perdas de umidade.

\section{Taxa respiratória}

A atividade respiratória foi representada por equações de segundo grau (Figura 2), sendo uma para o tratamento 1, uma para os tratamentos 2 e 3 e uma para os tratamentos 4 e 5 . Observa-se que os tratamentos 2 e 3 tiveram um comportamento diferente dos demais. A taxa respiratória mostra o comportamento climatérico das jabuticabas, conforme descrito por Corrêa et al. (2007). Esse tipo de metabolismo respiratório refletiu-se na variação dos teores de SS (Figura 3) e nos constantes decréscimos nos níveis de acidez (Figura 4).

Os frutos submetidos a temperaturas acima de $9^{\circ} \mathrm{C}$ apresentaram maior produção de $\mathrm{CO}_{2}$, quando em comparação aos frutos dos demais tratamentos ao final do experimento, que apresentavam distúrbios fisiológicos ocasionados pelas baixas temperaturas durante o AR. Pressupõe-se, para a jabuticabas refrigeradas acima de $9^{\circ} \mathrm{C}$, estádio menos avançado de amadurecimento, quando também analisados os maiores teores de SS e níveis de acidez detectados na mesma época, nos demais tratamentos. Entretanto, para os frutos refrigerados nas temperaturas de $0 ; 3$ e $6^{\circ} \mathrm{C}$, como resposta fisiológica ao dano de frio, observou-se a antecipação do pico climatérico para 15 dias (frutos a $0^{\circ} \mathrm{C}$ ) e 20 dias (frutos a 3 e $6^{\circ} \mathrm{C}$ ), induzindo-os rapidamente à senescência. Da mesma forma, após esse período, também se observam constantes decréscimos nos teores de sólidos solúveis e nos conteúdos de acidez nesses frutos. Esses resultados, conforme afirmado por Fonseca et al. (2003), podem estar relacionados à utilização desses compostos como substrato respiratório. Nesse sentido, o incremento na produção de $\mathrm{CO}_{2}$ (respiração) ou, por assim dizer, o pico climatérico nesses frutos, ocorreu de maneira prematura, sendo necessária então a produção endógena de energia para a sobrevivência dos frutos após o período de máxima descarboxilação. Baseando-se no fato de que todo e qualquer processo respiratório é sempre de natureza degradativa, tendo como função primordial a produção de energia e intermediários metabólitos, pressupõe-se para esses frutos menor potencial de conservabilidade.

\section{Conteúdo de sólidos solúveis, acidez titulá- vel e ácido ascórbico}

Como consequência do metabolismo respiratório climatérico, os teores de sólidos solúveis das jabuticabas incrementaram ao longo do período experimental, atingindo pontos de máximo em diferentes momentos do AR, de acordo com cada tratamento. A partir daí, prestando-se como susbtrato energético para a transformação e sobrevivência pós-colheita de alguns frutos (FONSECA et al., 2003), observaramse progressivos decréscimos nos teores de sólidos solúveis. Isso, como já afirmado, pode corroborar a determinação do estádio de maturidade em que os frutos se encontravam. Essa informação pode ser verificada na Figura 3, pelas equações de segundo grau. Foi obtida uma equação para o tratamento 1 , uma para os tratamentos 2 e 3 e uma para os tratamentos 4 e 5. Os tratamentos 4 e 5 tiveram um comportamento bem diferente dos demais.

Desta maneira, diferentemente dos frutos refrigerados em temperaturas abaixo de $9^{\circ} \mathrm{C}$, observouse que os frutos submetidos às temperaturas de $9 \mathrm{e}$ $12^{\circ} \mathrm{C}$ apresentaram constantes acréscimos nos teores de sólidos solúveis. Nesses tratamentos, o teor médio de sólidos solúveis encontrado ficou entre 17,9 e $17,3^{\circ}$ Brix, alcançado somente aos 30 dias após a instalação do experimento. Esses resultados são considerados relevantes quanto à qualidade final, visto que, segundo Brunini et al. (2004), o teor de SS pode ser relacionado à determinação do sabor do fruto.

Por outro lado, o teor médio de sólidos solúveis de $17,9^{\circ} \mathrm{Brix}$ dos frutos refrigerados a $0^{\circ} \mathrm{C}$ e de $17,6^{\circ}$ Brix dos frutos nas temperaturas de 3 e $6^{\circ} \mathrm{C}$, foram alcançados, respectivamente, aos 10 e 15 dias de AR. Esses períodos corresponderam, por sua vez, ao estádio de ascensão climatérica nesses frutos.

A acidez foi representada por equações de segundo grau, sendo uma para o tratamento 1, uma para os tratamentos 2 e 3 e uma para os tratamentos 4 e 5 (Figura 4). A exemplo do que ocorreu com os sólidos solúveis, também puderam indicar o estádio de maturação e/ou auxiliar na caracterização da qualidade dos próprios frutos. Nos frutos de todos os tratamentos, de maneira constante, observaram-se decréscimos nos níveis de acidez. Esse resultado está de acordo com os estudos de Pech (2002), onde se menciona que a redução da acidez é decorrência natural da evolução da maturação dos frutos, na qual os ácidos orgânicos são metabolizados na via respiratória e convertidos em moléculas não ácidas.

Deste modo, observou-se que os níveis de 
acidez variaram entre 0,855 e $0,850 \mathrm{~g}$ de ácido cítrico. $100 \mathrm{~g}^{-1}$ de polpa nos frutos refrigerados a $9 \mathrm{e}$ $12^{\circ} \mathrm{C}$, ou seja, perdas médias que não ultrapassaram a $29 \%$ quando em comparação à instalação do experimento. Entretanto, nos frutos submetidos a temperaturas inferiores a $9^{\circ} \mathrm{C}$, foram detectadas perdas médias de acidez que variaram de 43 a $63 \%$ em relação aos níveis iniciais de AR das jabuticabas. Pech (2002) afirma que o decréscimo da acidez durante a póscolheita é natural e, segundo Neves et al. (2006), a velocidade com que ocorre também pode servir como indicador da evolução do amadurecimento dos frutos.

$\mathrm{O}$ teor de ácido ascórbico foi representado por equações de segundo grau, sendo uma para o tratamento 1 , uma para os tratamentos 2 , uma para o tratamento 3 e uma para os tratamentos 4 e 5 (Figura 5). Assim como a acidez, o teor de ácido ascórbico também apresentou constante decréscimo. Contudo, isso até certo ponto era esperado, visto que o ácido ascórbico em jaboticabas, bem como na maioria dos frutos, diminui durante a pós-colheita (NEVES et al., 2008b). O diferencial então consistiria em por quanto tempo cada fruto, exposto às diferentes temperaturas de AR, conseguiria mantê-lo. Nesse sentido, os frutos submetidos à refrigeração a $9 \mathrm{e} 12^{\circ} \mathrm{C}$, mais uma vez, apresentaram os melhores resultados, denotando-se perdas médias inferiores a 30\% em relação aos conteúdos iniciais. Esses resultados são considerados importantes, pois o ácido ascórbico, além das propriedades funcionais já conhecidas, também pode atuar como agente antioxidante no próprio fruto, contribuindo positivamente na preservação da qualidade durante o AR. Já nos demais tratamentos, os frutos apresentaram perdas médias de até $62 \%$. Essas perdas podem ter ocorrido pelo fato de que os ácidos orgânicos, dentre os quais o ascórbico, são consumidos em reações oxidativas durante a maturação e a senescência dos frutos.

\section{Textura, pectina total e solúvel}

As jabuticabas, independentemente das condições de refrigeração testadas, perderam, gradativamente, a rigidez dos tecidos no decorrer do experimento. Este fato pôde ser constatado pelas equações de segundo grau, sendo uma para os tratamentos $1 \mathrm{e}$ 2, uma para o tratamento 3 e uma para os tratamentos 4 e 5 (Figura 6). Dessa forma, pode-se reafirmar que a perda de firmeza seja normal durante a póscolheita (BÁEZ-SAÑUDO et al., 2001). Contudo, também se deve levar em consideração que a firmeza é um importante atributo na qualidade dos frutos, já que afeta a resistência ao transporte, o ataque de microrganismos e a própria característica sensorial dos fruto. Assim, a melhor preservação da firmeza das jabuticabas, observada quando refrigeradas a 9 e $12^{\circ} \mathrm{C}$, pode sugerir também a melhor integridade dos tecidos celulares e, consequentemente, o retardo no avanço do amadurecimento e da senescência desses frutos. Brackmann et al. (2005) sugerem que frutos com acelerada taxa respiratória, como é caso das jabuticabas, necessitam de adequado controle atmosférico para a diminuição da velocidade dos eventos que desencadeiam o amadurecimento e a senescência. Dessa maneira, a utilização do PEBD, como cobertura à embalagem de EPS, associada às temperaturas de 9 e $12^{\circ} \mathrm{C}$ foram eficientes no propósito de aumentar a vida de prateleira e, o mais importante, com a preservação dos atributos de qualidade exigidos pelo mercado consumidor.

Entretanto, possivelmente como reflexo do distúrbio fisiológico causado pelas baixas temperaturas, os frutos submetidos à refrigeração em temperaturas inferiores a $9^{\circ} \mathrm{C}$ apresentaram perdas relevantes no que concerne à textura inicial dos frutos. Em média, esses tratamentos apresentaram perdas de até $46 \%$ da textura, enquanto nos frutos submetidos às temperaturas de 9 e $12^{\circ} \mathrm{C}$, essas perdas não ultrapassaram a $27 \%$ dos valores iniciais. Condiciona-se esse resultado à diminuição na velocidade dos processos metabólicos, proporcionando, por maior período de tempo, a preservação das cadeias pécticas da parede celular polimerizadas, influenciando na manutenção da textura dos frutos durante o AR.

Assim, os frutos que apresentaram os maiores valores em relação à textura (frutos a $9 \mathrm{e}$ $12^{\circ} \mathrm{C}$ ), também apresentaram os menores conteúdos de pectina solúvel ao final do experimento. Por outro lado, os frutos refrigerados a $0 ; 3$ e $6^{\circ} \mathrm{C}$, que apresentaram metabolismo respiratório acelerado (Figura 2) e antecipação do pico climatérico, também apresentaram os menores valores de textura (Figura 6) e os maiores conteúdos de pectina solúvel aos 30 dias de AR.

Em contraposição, as medidas de pectina total não variaram nos frutos, sendo que o conteúdo médio encontrado foi de $618 \mathrm{mg} .100 \mathrm{~g}^{-1}$ de polpa. O comportamento da pectina total, no presente experimento, é concordante com o estudo de Freire Júnior e Chitarra (1999), em que esses autores observaram que a pectina total não foi significativamente alterada durante o período de AR.

\section{Atividade da enzima polifenoloxidase}

Constatou-se o decréscimo na atividade da polifenoloxidase à medida que o período de armazenamento aumentava, conforme apresentado na Figura 8 pela regressão linear única obtida para os 5 tratamentos. 
Por ser encontrada praticamente em todos os tecidos vegetais (CÔRREA et al., 2007), e sua atividade ser dependente da espécie, das condições de cultivo e do estádio de maturação (MARTINS et al., 2004), a análise da atividade da enzima polifenoloxidase também corroborou a constatação da qualidade das jabuticabas. Dessa maneira, verificou-se que a atividade da polifenoloxidase decresceu ao longo dos 30 dias de AR, independentemente da temperatura de refrigeração. Contudo, o comportamento da enzima PFO é variável e dependente da matriz do fruto. Por exemplo, em maçãs, verificou-se o aumento na atividade ao longo do amadurecimento (COSETENG;LEE, 1987), enquanto para pêssegos, assim como observado nas jabuticabas, o comportamento foi contrário (BASSI; SELLI, 1990).

Embora não tenham sido verificadas diferenças estatísticas significativas para a atividade enzimática $\mathrm{PFO}$, nos frutos submetidos a temperaturas de 9 e $12^{\circ} \mathrm{C}$ por 30 dias, observou-se menor atividade, quando comparados aos demais frutos refrigerados em temperaturas inferiores, que apresentaram maior atividade. Nesse sentido, pode-se admitir que essa diferença esteja relacionada ao estresse oxidativo causado pelo dano de frio, em que os frutos refrigerados em temperatura igual ou superior a $9^{\circ} \mathrm{C}$, que apresentam menor aceleração do metabolismo respiratório, também demostraram menor atividade da polifenoloxidase ao final do período experimental, enquanto nos frutos refrigerados nas temperaturas de $0 ; 3$ e $6^{\circ} \mathrm{C}$, não só pelo metabolismo respiratório, mas também como reflexo da sensibilidade dos frutos ao calor reduzido, a atividade da polifenoloxidase foi mais elevada. Portanto, é possível afirmar que a elevação da atividade da polifenoloxidase seja decorrente dos efeitos deletérios causados pelas baixas temperaturas utilizadas.

\section{Conteúdo de compostos fenólicos totais e atividade antioxidante}

Para os compostos fenólicos totais, foram obtidas equações de segundo grau, sendo uma para o tratamento 1, uma para os tratamentos 2 e 3, uma para o tratamento 4 e uma para o tratamento 5. Pelos resultados observados na Figura 9, as jabutibacas, no início do experimento, apresentavam conteúdos médios de compostos fenólicos totais na ordem de 4.089 mg EAG.100g ${ }^{-1}$. Nesse contexto, Silva et al. (2004) mencionam que a presença desses compostos nos alimentos pode proporcionar efeitos benéficos à saúde humana. Esses dados são concordantes com pesquisas recentes, onde é demonstrado que as propriedades de vários compostos fenólicos, presentes em frutos, atuam com eficácia nas infecções causadas por Helicobacter pylori e na indução da apoptose (YEH; YEN, 2005).

Contudo, para todos os frutos, durante o período experimental, observaram-se decréscimos nos conteúdos de compostos fenólicos totais. Assim, dentre os tratamentos estudados, os frutos sumetidos à temperatura de $12^{\circ} \mathrm{C}$ foram os que melhor preservaram o conteúdo desses compostos ao final do experimento, em média $3.228 \mathrm{mg}$ EAG.100g-1 de amostra seca, seguidos dos frutos submetidos à temperatura de $9^{\circ} \mathrm{C}$, em média $1.005 \mathrm{mg}$ EAG. $100 \mathrm{~g}^{-1}$ de amostra seca. Os frutos que caracterizaram os menores conteúdos de fenólicos totais, no final do estudo, foram aqueles submetidos a temperaturas de $0 ; 3$ e $6{ }^{\circ} \mathrm{C}$, apresentando valores médios de $55,45 \mathrm{mg}$ EAG. $100 \mathrm{~g}^{-1}$ de amostra seca ao final dos 30 dias de AR. Esse decréscimo pode ser atribuído à série de alterações químicas e enzimáticas de determinados fenóis durante o processo acelerado de amadurecimento desses frutos. Podem-se incluir a essas alterações as hidrólises de glicosídeos por glicosidases, a oxidação de fenóis por fenoloxidases e a polimerização de fenóis livres (ROBARDS et al., 1999).

Apesar de o conteúdo de componentes fenólicos totais não necessariamente estar envolvido na quantificação da atividade antioxidante (JACOBOVELASQUÉZ; CISNEROS-ZEVALLOS, 2009), os resultados dessa análise nas jabuticabas (Figuras $10 \mathrm{e}$ 11), avaliados por 2 métodos distintos, apresentaram correlação com diminuição dos mesmos ao longo do experimento.

A atividade antioxidante ORAC (Figura 10) foi representada por equações de segundo grau, sendo uma para o tratamento 1, uma para os tratamentos $2 \mathrm{e}$ 3, uma para o tratamento 4 e uma para o tratamento 5 . A atividade antioxidante DPPH • (Figura 11) também foi representada por equações de segundo grau, sendo uma para o tratamento 1, uma para os tratamentos $2 \mathrm{e}$ 3, uma para o tratamento 4 e uma para o tratamento 5 .

Desse modo, os frutos que apresentaram os maiores conteúdos de fenólicos, ao final do estudo, também apresentaram os maiores valores ORAC (400 $\mu$ mols de TE. $100 \mathrm{~g}^{-1}$ de polpa) e DPPH• (391 $\mu$ mols de TE. $100 \mathrm{~g}^{-1}$ de polpa). As menores atividades antioxidantes observadas foram nos frutos refrigerados nas temperaturas de $0 ; 3$ e $6^{\circ} \mathrm{C}$. Esses valores, aos 30 dias de AR, apresentaram médias de 54,5 e $50,8 \mu$ mols de TE. $100 \mathrm{~g}^{-1}$ de polpa para ORAC e $\mathrm{DPPH}^{-1}$, respectivamente. Assim, pressume-se que a menor atividade antioxidante estaria ligada ao distúrbio fisiológico nos frutos. 


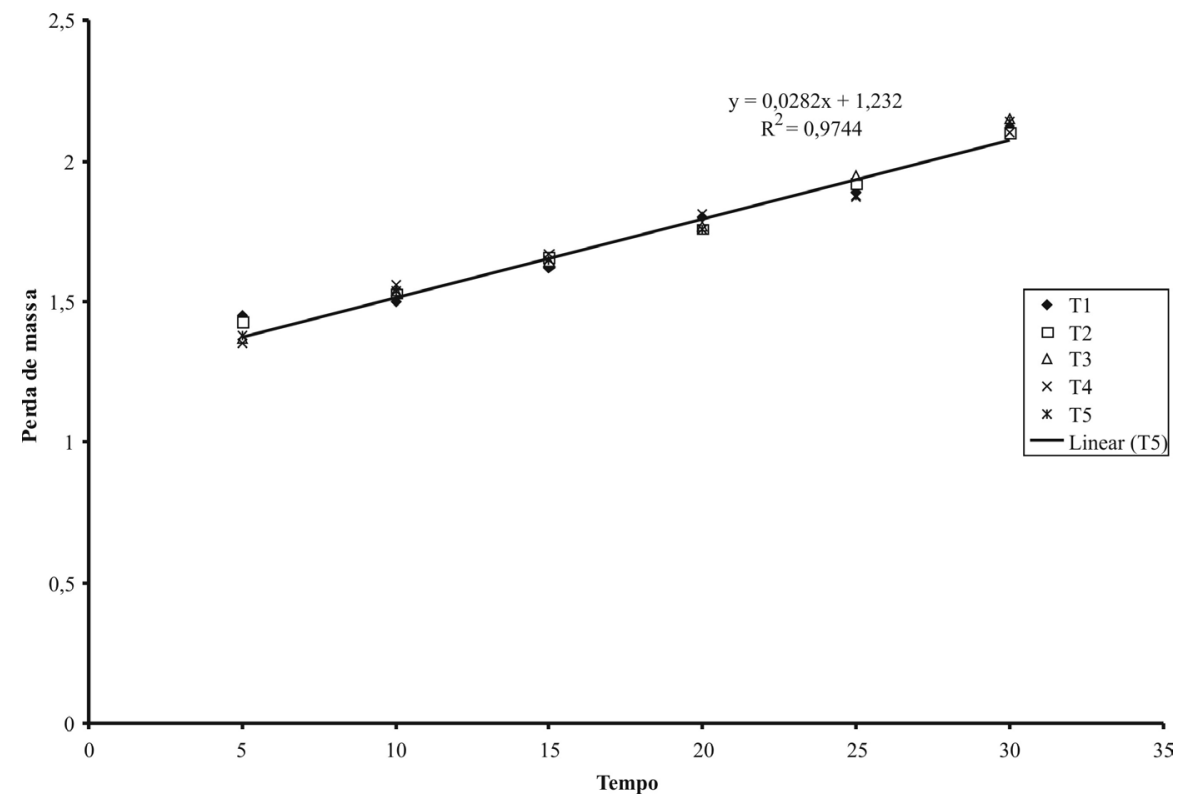

FIGURA 1- Percentual da perda de massa da jabuticaba armazenada por 30 dias, sob diferentes temperaturas: $\left(\mathrm{T} 1=0{ }^{\circ} \mathrm{C} ; \mathrm{T} 2=3 ; \mathrm{T} 3=6{ }^{\circ} \mathrm{C} ; \mathrm{T} 4=9{ }^{\circ} \mathrm{C} ; \mathrm{T} 5=12{ }^{\circ} \mathrm{C}( \pm 1\right.$ e $\mathrm{UR}=87 \pm 2 \%)$.

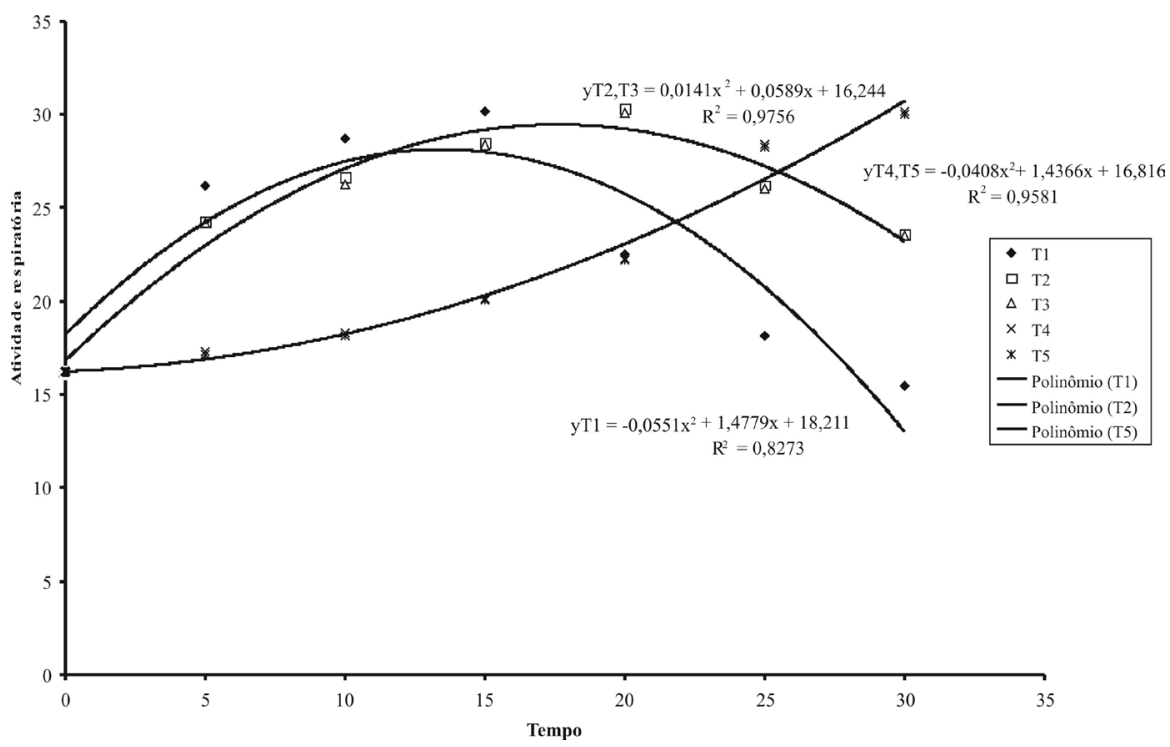

FIGURA 2- Atividade respiratória $\left(\mathrm{mL}\right.$ de $\left.\mathrm{CO}_{2} \cdot \mathrm{kg}^{-1} \cdot \mathrm{h}^{-1}\right)$ de jabuticabas armazenadas sob refrigeração por 30 dias, sob diferentes temperaturas: $\left(\mathrm{T} 1=0{ }^{\circ} \mathrm{C} ; \mathrm{T} 2=3 ; \mathrm{T} 3=6{ }^{\circ} \mathrm{C} ; \mathrm{T} 4=9{ }^{\circ} \mathrm{C} ; \mathrm{T} 5=12{ }^{\circ} \mathrm{C}( \pm 1 \mathrm{e}\right.$ $\mathrm{UR}=87 \pm 2 \%$ ) 


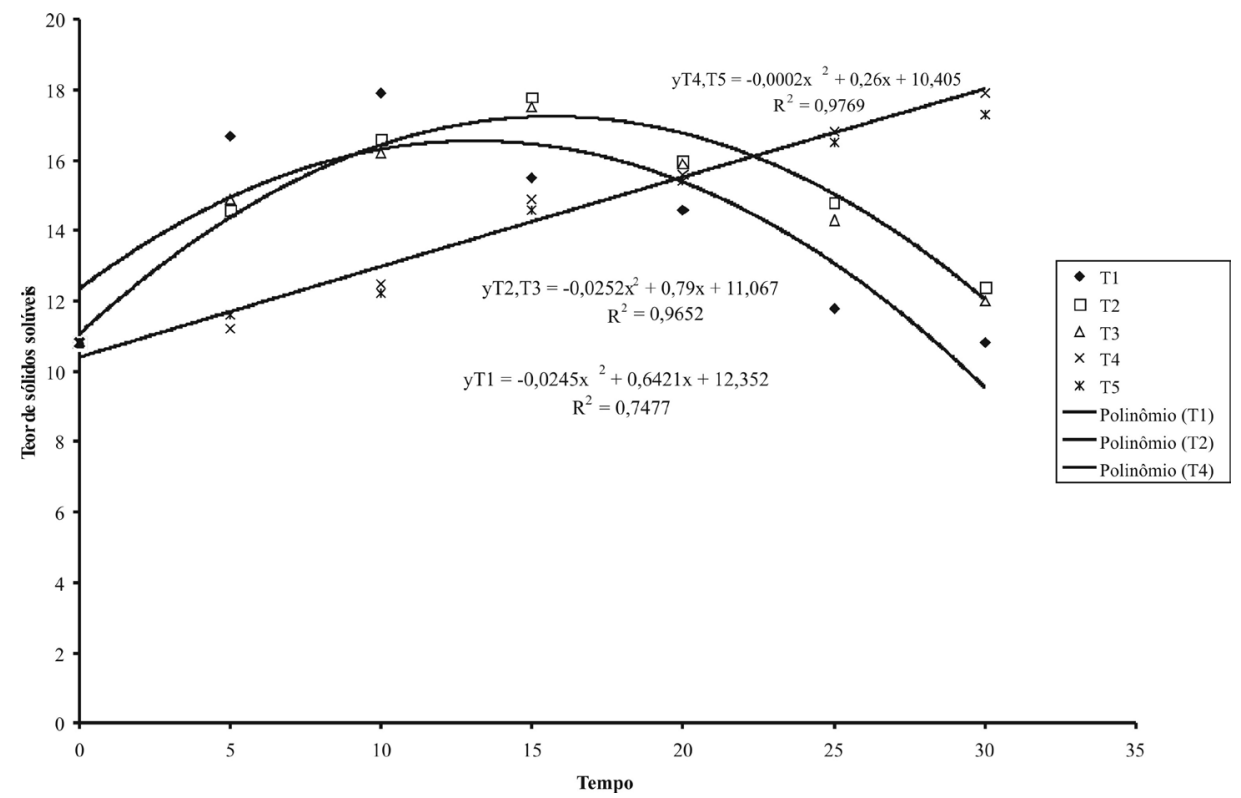

FIGURA 3- Teor de sólidos solúveis ( ${ }^{\circ}$ Brix) de jabuticabas armazenadas sob refrigeração por 30 dias, sob diferentes temperaturas. $\left(\mathrm{T} 1=0{ }^{\circ} \mathrm{C} ; \mathrm{T} 2=3 ; \mathrm{T} 3=6^{\circ} \mathrm{C} ; \mathrm{T} 4=9^{\circ} \mathrm{C} ; \mathrm{T} 5=12{ }^{\circ} \mathrm{C}( \pm 1\right.$ e UR $=87 \pm 2 \%)$.

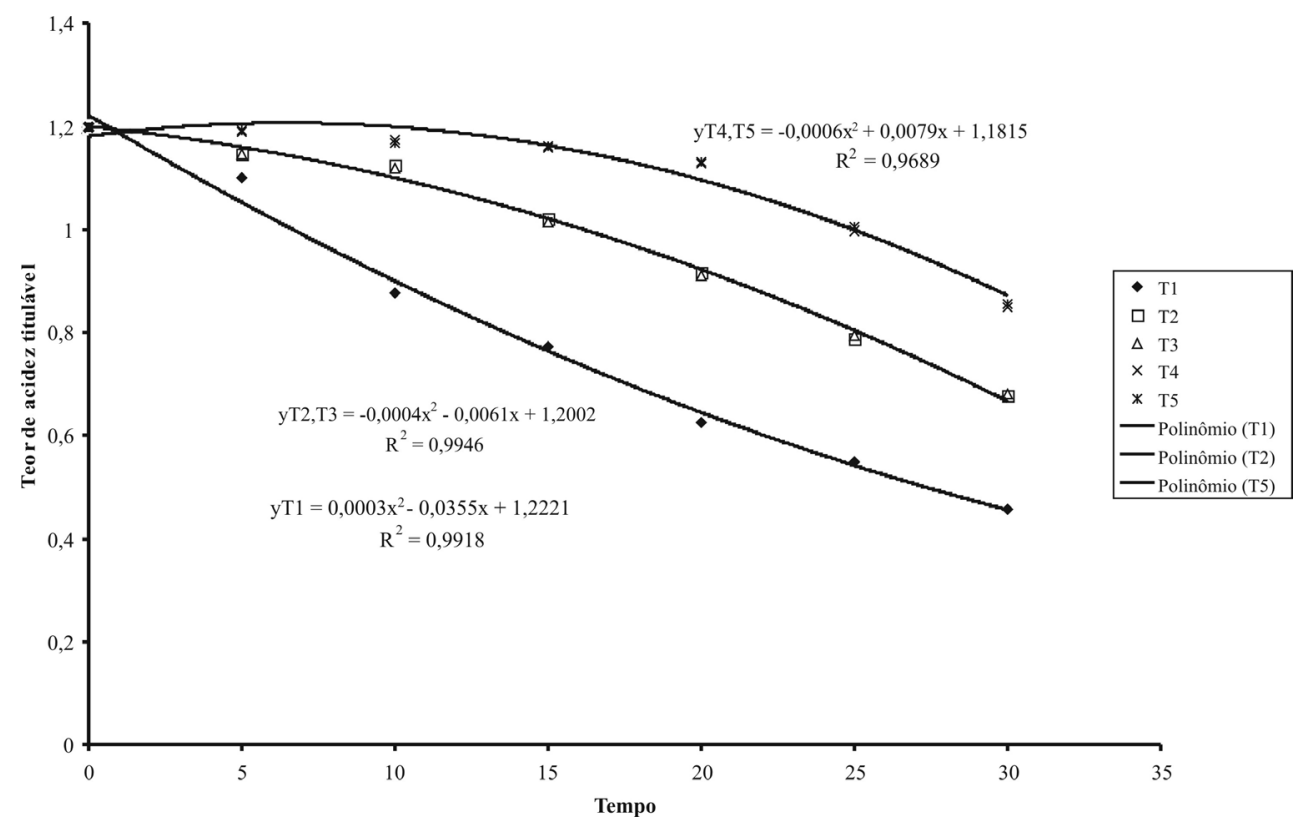

FIGURA 4- Conteúdo de acidez titulável ( $\mathrm{g}$ de ácido cítrico.100g polpa $\left.{ }^{-1}\right)$ de jabuticabas armazenadas sob refrigeração por 30 dias, sob diferentes temperaturas: $\left(\mathrm{T} 1=0{ }^{\circ} \mathrm{C} ; \mathrm{T} 2=3 ; \mathrm{T} 3=6^{\circ} \mathrm{C} ; \mathrm{T} 4=9^{\circ} \mathrm{C}\right.$; $\mathrm{T} 5=12{ }^{\circ} \mathrm{C}( \pm 1$ e UR $=87 \pm 2 \%)$. 


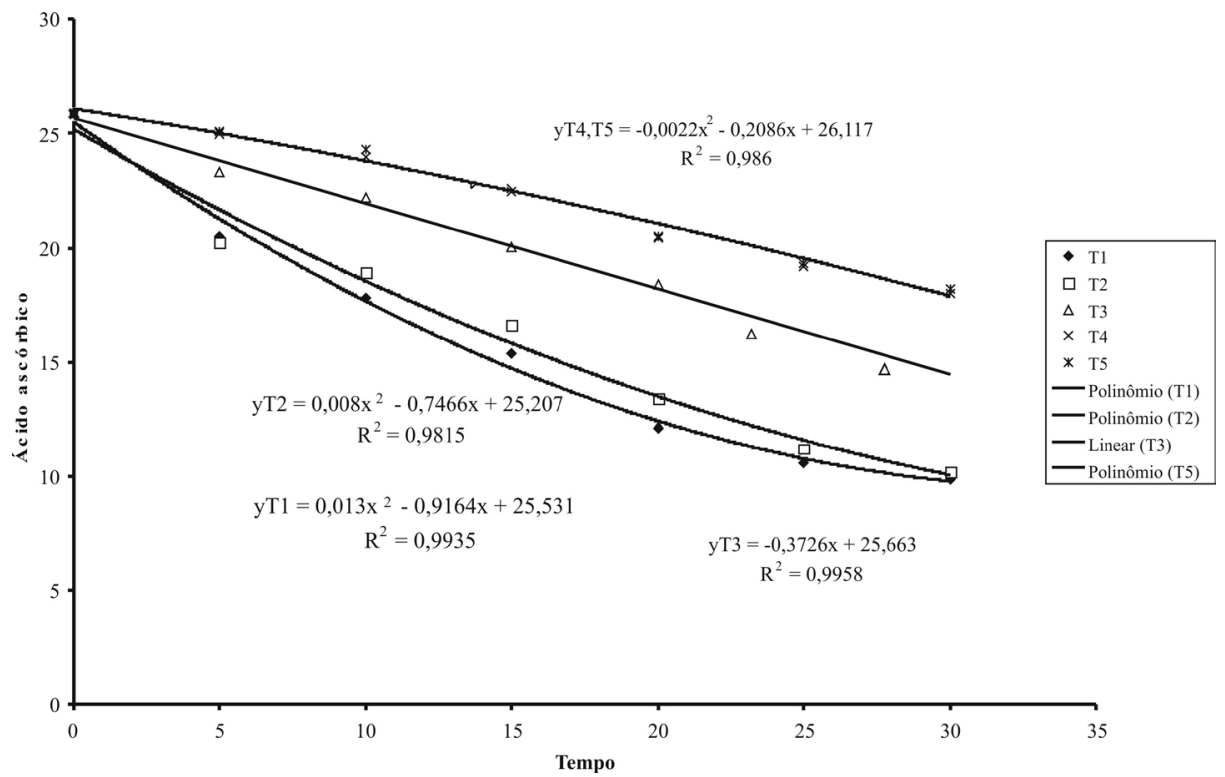

FIGURA 5- Teor de ácido ascórbico $\left(\mathrm{g} .100 \mathrm{~g}^{-1}\right)$ de jabuticabas armazenadas sob refrigeração por 30 dias, sob diferentes temperaturas: $\left(\mathrm{T} 1=0{ }^{\circ} \mathrm{C} ; \mathrm{T} 2=3 ; \mathrm{T} 3=6^{\circ} \mathrm{C} ; \mathrm{T} 4=9^{\circ} \mathrm{C} ; \mathrm{T} 5=12^{\circ} \mathrm{C}( \pm 1\right.$ e UR $=87 \pm 2 \%)$.

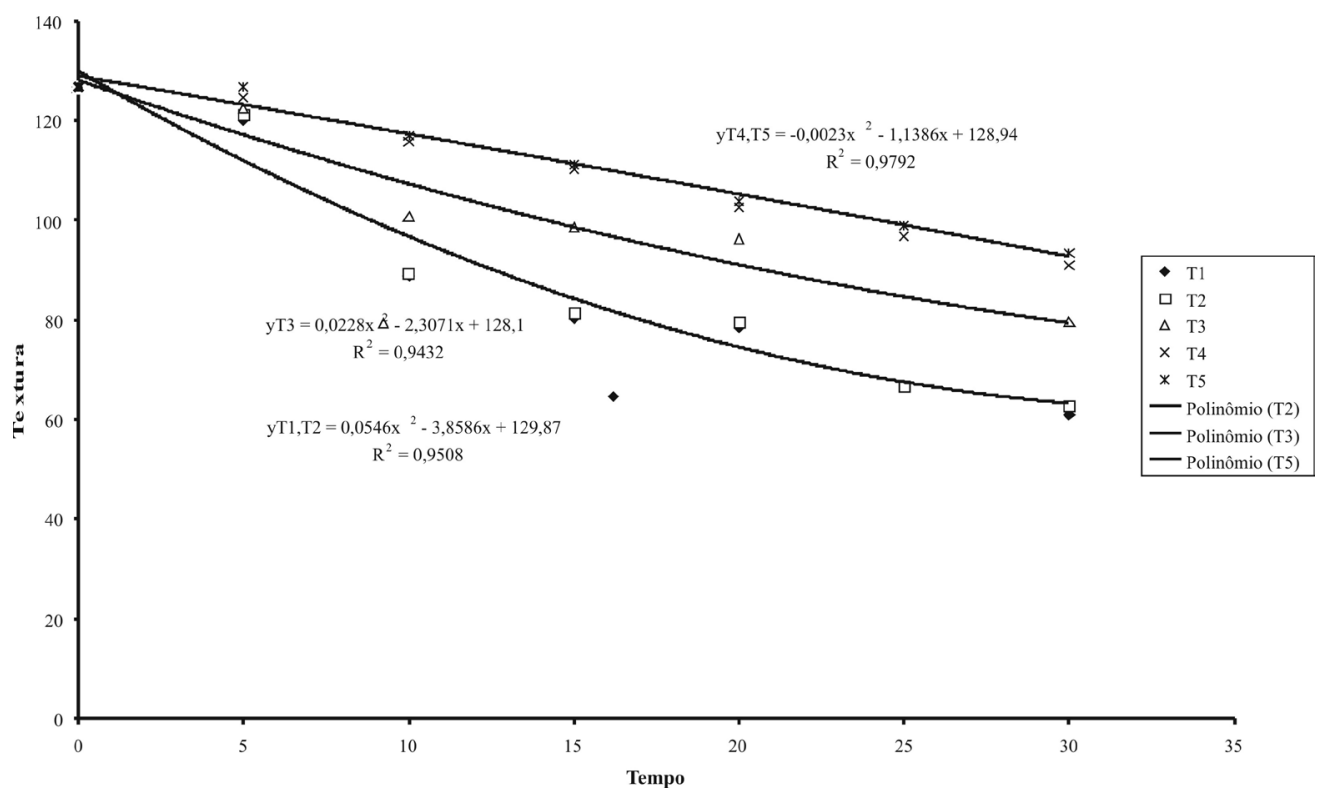

FIGURA 6-Firmeza (f. $\left.\mathrm{g}^{-1}\right)$ da de jabuticabas armazenadas sob refrigeração por 30 dias, sob diferentes temperaturas: $\left(\mathrm{T} 1=0{ }^{\circ} \mathrm{C} ; \mathrm{T} 2=3 ; \mathrm{T} 3=6{ }^{\circ} \mathrm{C} ; \mathrm{T} 4=9{ }^{\circ} \mathrm{C} ; \mathrm{T} 5=12{ }^{\circ} \mathrm{C}( \pm 1\right.$ e UR $=87 \pm 2 \%)$. 


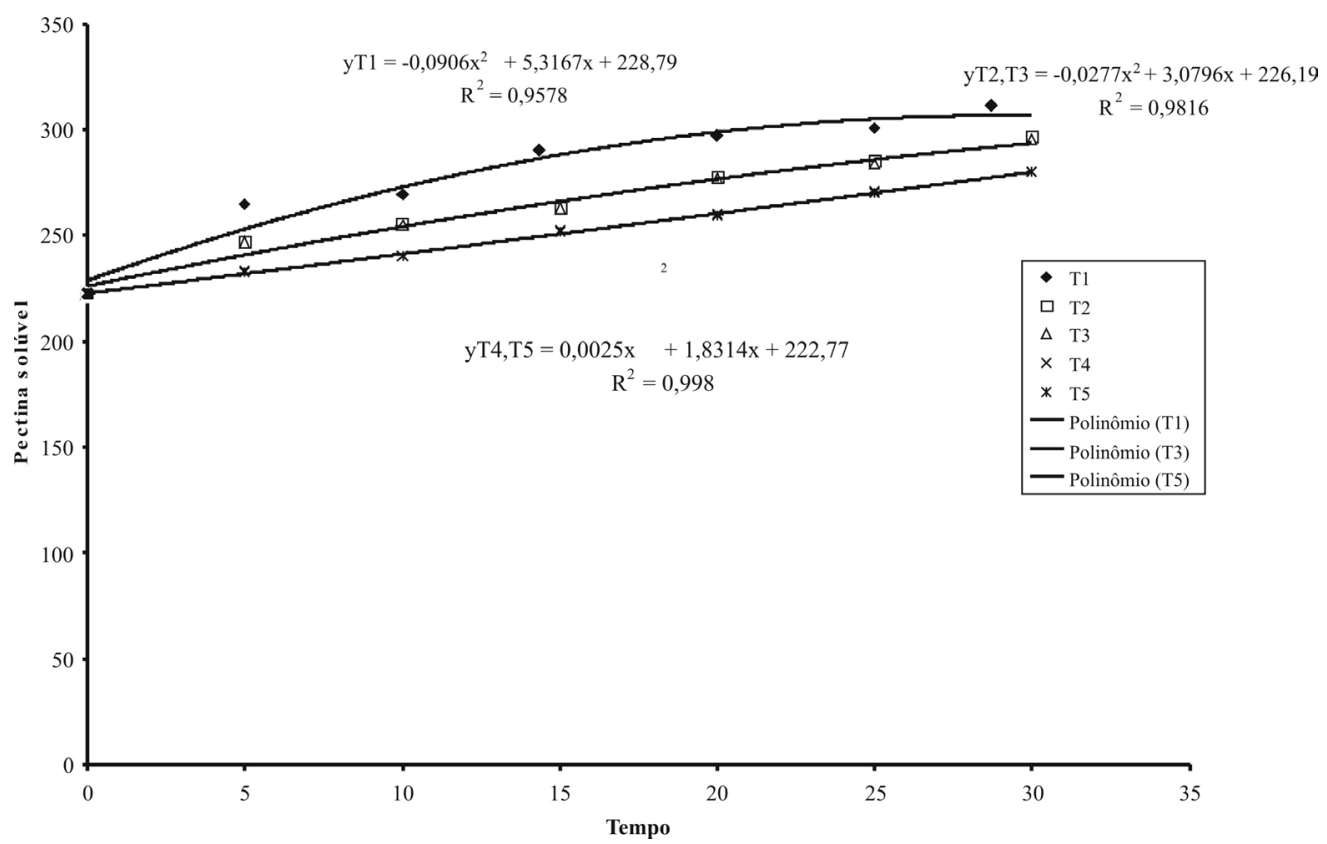

FIGURA 7- Pectina solúvel (mg.100g ${ }^{-1}$ de polpa) de jabuticabas armazenadas sob refrigeração por 30 dias, sob diferentes temperaturas: $\left(\mathrm{T} 1=0{ }^{\circ} \mathrm{C} ; \mathrm{T} 2=3 ; \mathrm{T} 3=6^{\circ} \mathrm{C} ; \mathrm{T} 4=9^{\circ} \mathrm{C} ; \mathrm{T} 5=12{ }^{\circ} \mathrm{C}( \pm 1\right.$ e UR $=87 \pm 2 \%)$.

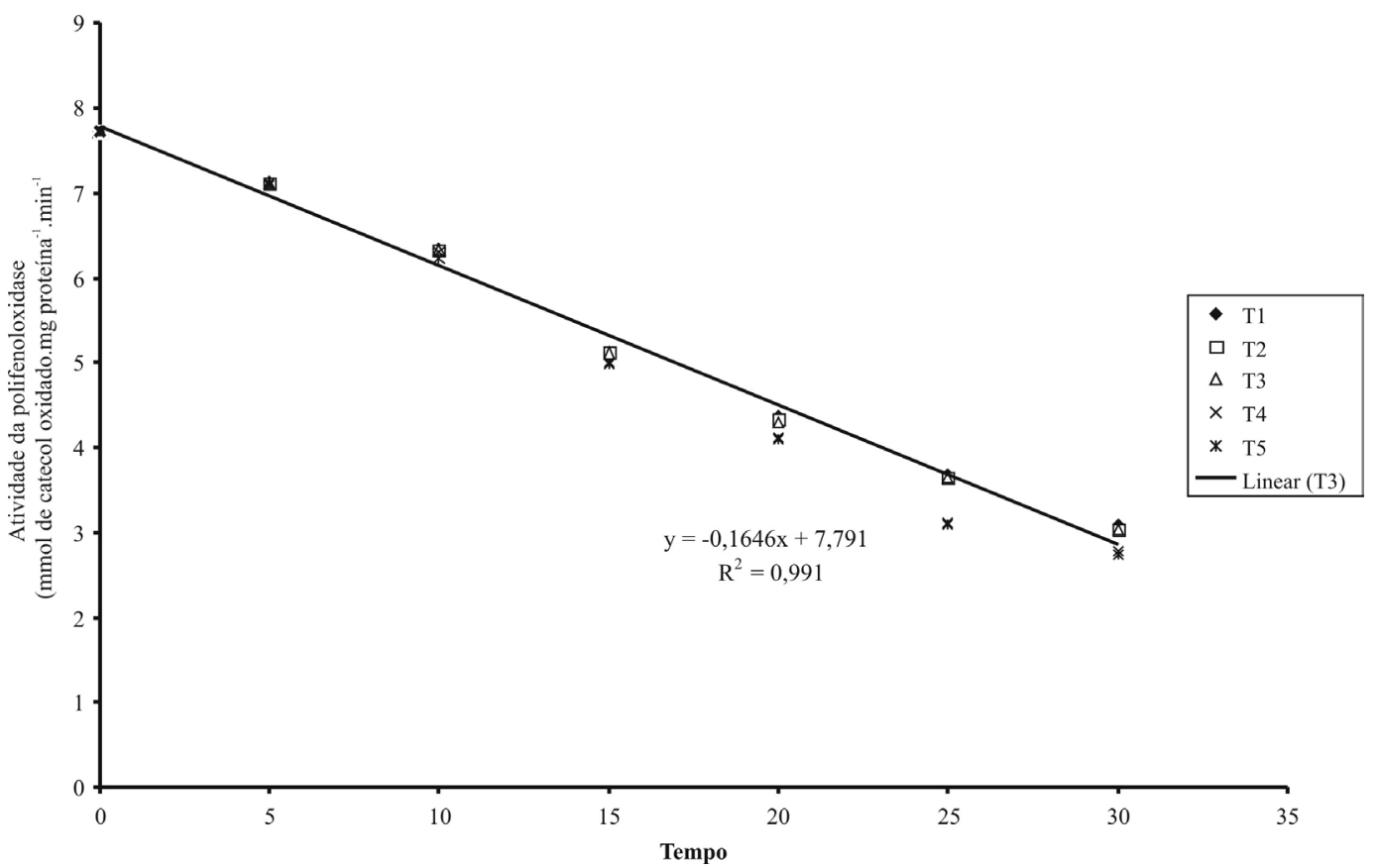

FIGURA 8- Atividade da polifenoloxidase ( $\mu \mathrm{mol}$ de catecol oxidado.mg proteína $\left.{ }^{-1} \cdot \mathrm{min}^{-1}\right)$ de jabuticabas armazenadas sob refrigeração por 30 dias, sob diferentes temperaturas: $\left(\mathrm{T} 1=0{ }^{\circ} \mathrm{C} ; \mathrm{T} 2=3 ; \mathrm{T} 3=\right.$ $6^{\circ} \mathrm{C} ; \mathrm{T} 4=9{ }^{\circ} \mathrm{C} ; \mathrm{T} 5=12{ }^{\circ} \mathrm{C}( \pm 1$ e UR $=87 \pm 2 \%)$. 


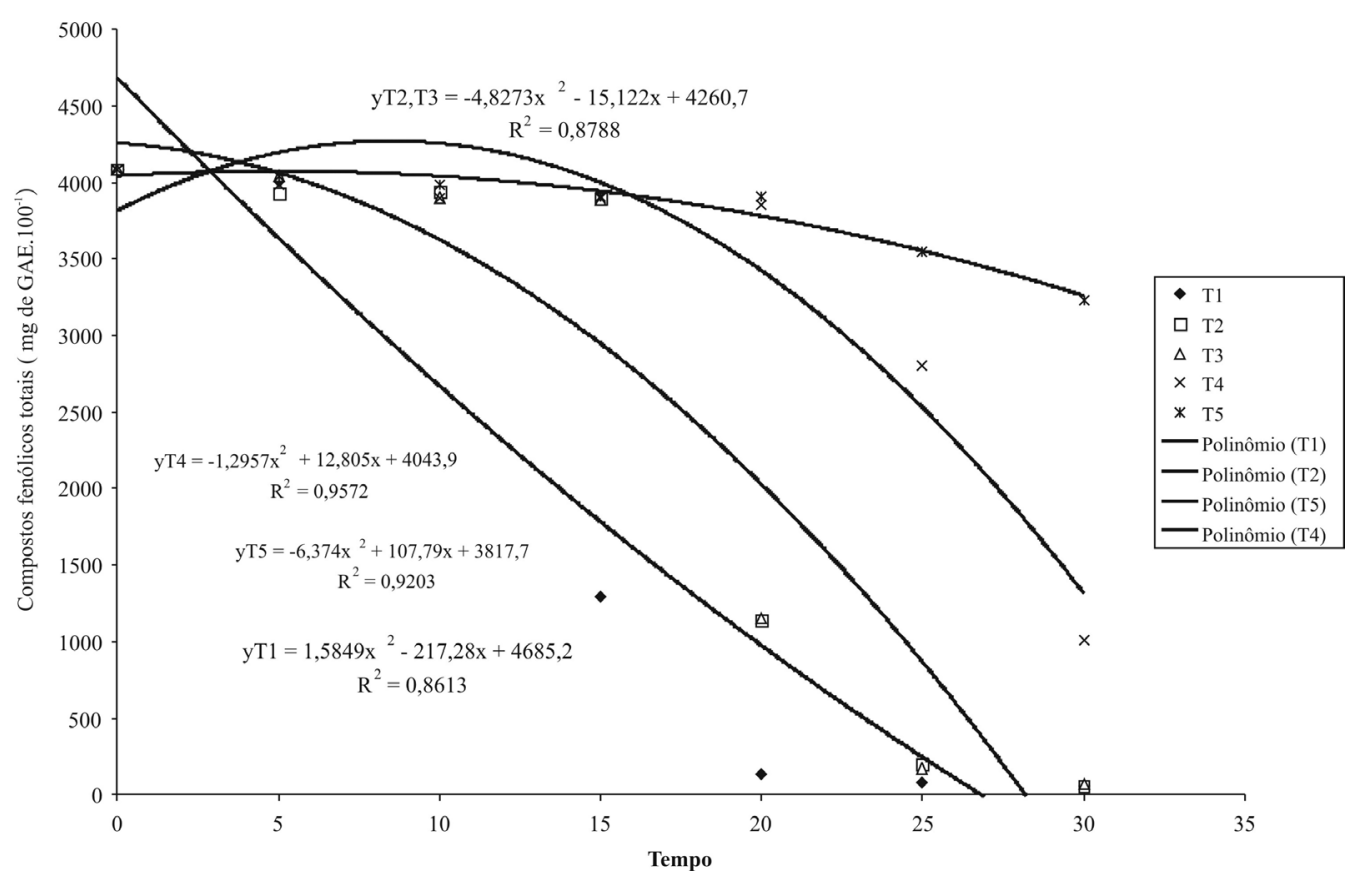

FIGURA 9- Compostos fenólicos totais (mg de GAE. $\left.100 \mathrm{~g}^{-1}\right)$ de jabuticabas armazenadas sob refrigeração por 30 dias, sob diferentes temperaturas. $\left(\mathrm{T} 1=0{ }^{\circ} \mathrm{C} ; \mathrm{T} 2=3 ; \mathrm{T} 3=6{ }^{\circ} \mathrm{C} ; \mathrm{T} 4=9{ }^{\circ} \mathrm{C} ; \mathrm{T} 5=12{ }^{\circ} \mathrm{C}\right.$ $( \pm 1$ e UR $=87 \pm 2 \%)$.

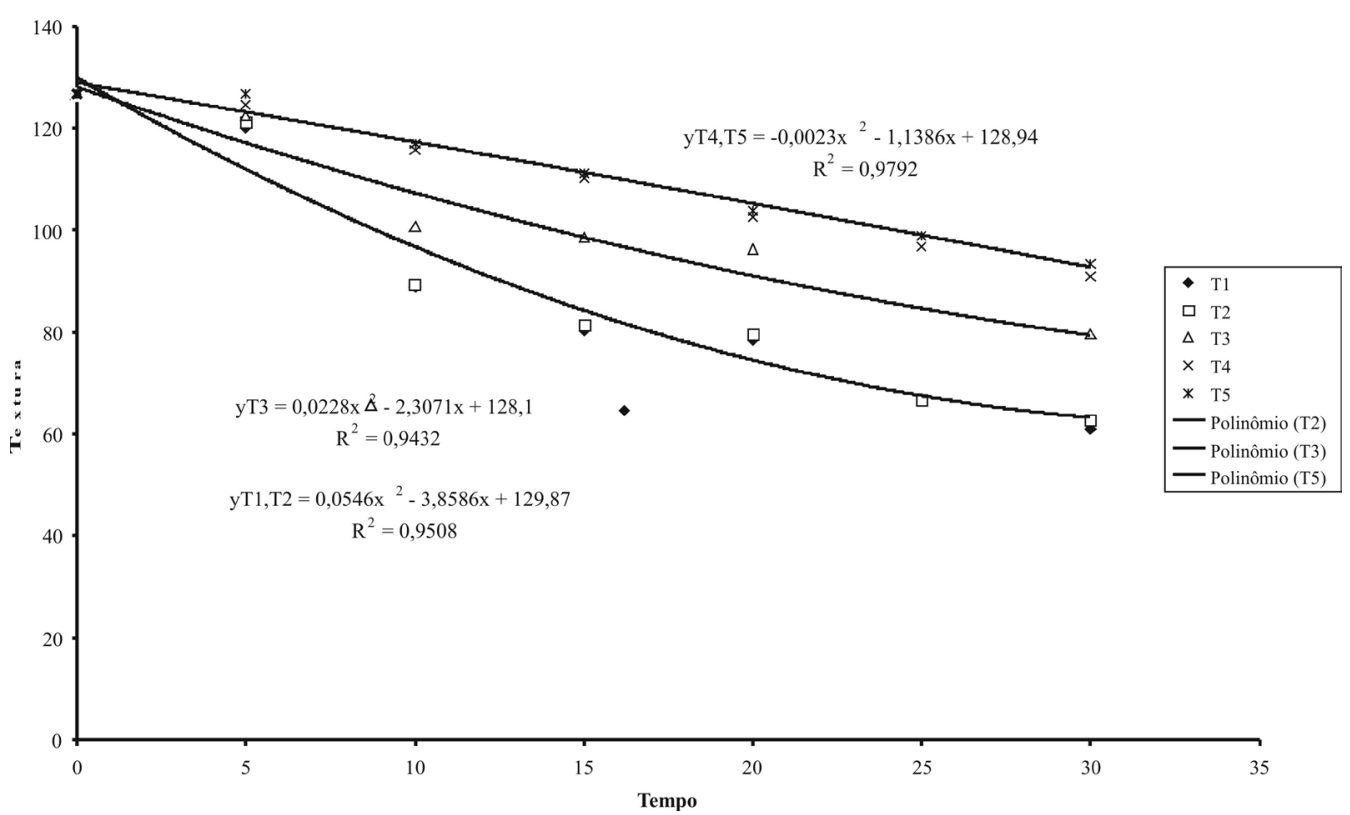

FIGURA 10- Atividade antioxidante ORAC (micromols de Trolox equivalents. g de polpa ${ }^{-1}$ ) de jabuticabas armazenadas sob refrigeração por 30 dias, sob diferentes temperaturas: $\left(\mathrm{T} 1=0{ }^{\circ} \mathrm{C} ; \mathrm{T} 2=3 ; \mathrm{T} 3=\right.$ $6{ }^{\circ} \mathrm{C}$; $\mathrm{T} 4=9{ }^{\circ} \mathrm{C} ; \mathrm{T} 5=12{ }^{\circ} \mathrm{C}( \pm 1$ e UR $=87 \pm 2 \%)$. 


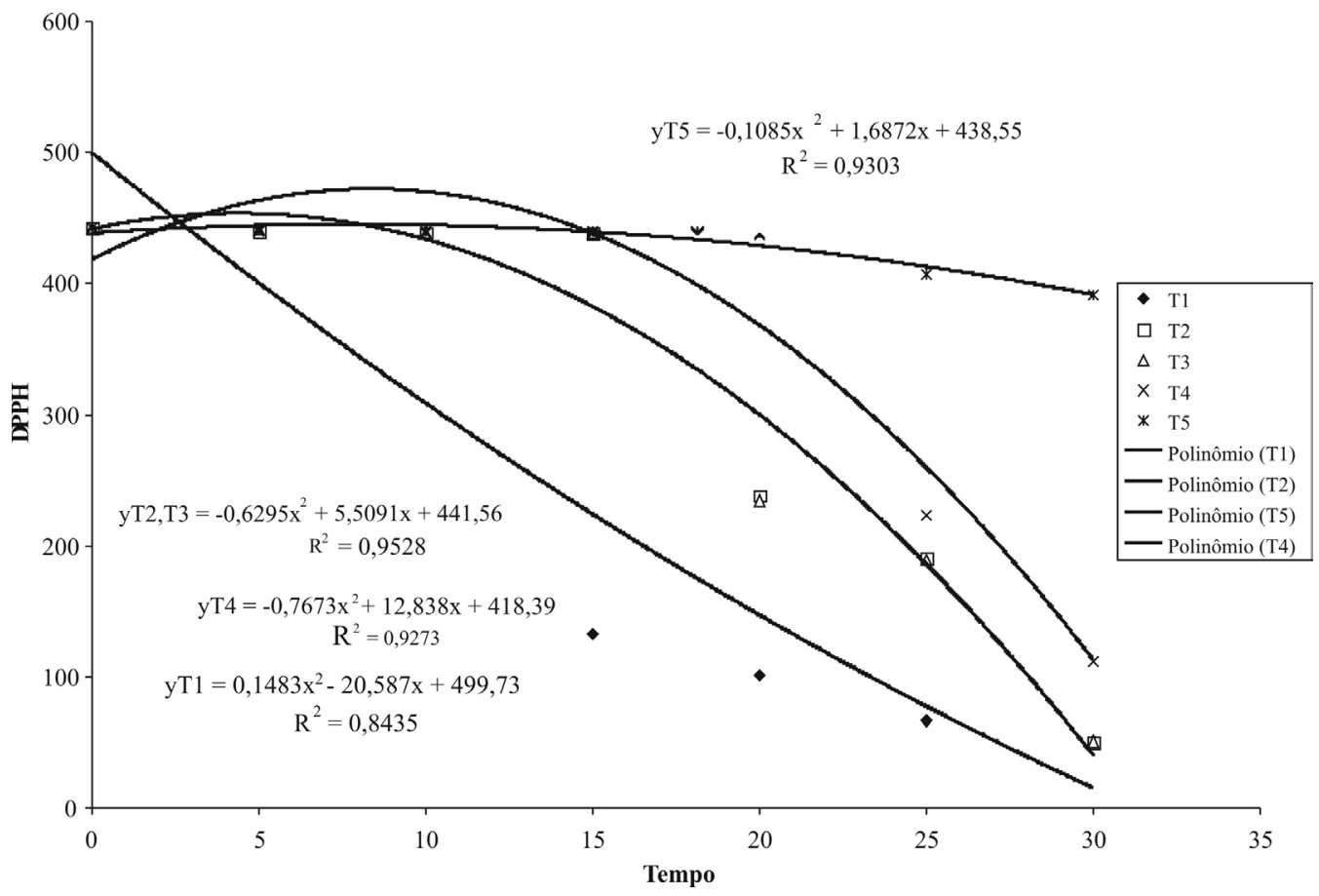

FIGURA 11- Atividade antioxidante DPPH• (micromols de Trolox equivalents. $\mathrm{g}$ de polpa $\left.{ }^{-1}\right)$ de jabuticabas armazenadas sob refrigeração por 30 dias, sob diferentes temperaturas: $\left(\mathrm{T} 1=0{ }^{\circ} \mathrm{C} ; \mathrm{T} 2=3 ; \mathrm{T} 3=\right.$ $6^{\circ} \mathrm{C} ; \mathrm{T} 4=9{ }^{\circ} \mathrm{C} ; \mathrm{T} 5=12{ }^{\circ} \mathrm{C}( \pm 1$ e UR $=87 \pm 2 \%)$.

\section{CONCLUSÃO}

De acordo com os resultados apresentados, a temperatura de $12^{\circ} \mathrm{C}$ pode ser considerada satisfatória na manutenção da qualidade funcional e bioquímica de jabuticabas da cultivar Sabará [M. Jaboticaba (Vell.) Berg.], por 30 dias de armazenamento refrigerado, em condições de atmosfera modificada.

\section{REFERÊNCIAS}

BÁEZ-SAÑUDO, R.; BRINGAS, T. E.; GONZÁLES, A. G.; OJEDA, C. J.; MENDOZA, W. A.; RAMOS, C. G. Evaluación de películas comestibles sobre la vida postcosecha del mango. Proceedings of the International Society Tropical Horticultural, Miami, v.41, p.172-178, 2001.

BASSI, D.; SELLI, R. Evaluation of fruit quality in peach and apricot. Advances in Horticultural Science, Firenze, v.4, p.107-112, 1990.

BLEINROTH, E.W.; ZUCHINI, A.G.; POMPEO, R.M. Determinação das características físicas e mecânicas de variedade de abacate e sua conservação pelo frio. Coletânea ITAL, Campinas, v.7. n.1, p.29-81, 1976.
BLOIS, M.S. Antioxidant determinations by the use of a stable free radical, Nature, London, n.181, p.1199-1200, 1958.

BLUMENKRANTZ, N.; ASBOE-HANSEN, G. New method for quantitative determination of uronic acids. Analitical Chemistry, New York, v.5, p.484489, 1973.

BRACKMANN, A.; GIEHL, R. F. H.; PINTO, J. A. V.; STEFFENS, C. A.; SESTARI, I. Qualidade de maçãs 'Gala' armazenadas em atmosfera controlada dinâmica e estática com renovação do ar. Ciência Rural, Santa Maria, v.35, n.2, p.465-467, 2005.

BRAND-WILIAMS, W.; CUVELIER, M. E.; BERSET, C. Use of a free radical method to evaluate antioxidant activity. Food Science and Technology, London, v.28, p.25-30. 1995.

BRUNINI, M.A.; OLIVIERA,A.L. de; SALANDINI, A. R.; BAZZO, F. R. Influência de embalagens e temperatura no armazenamento de jabuticaba (Myrciaria jabuticaba (Vell) Berg) cv Sabará. Ciência e Tecnologia de Alimentos,Campinas, v.24, n.3, p.378-383. 2004. 
CANO, M. P.; ANCOS, B. de; MANTALLANA, M. C.; CÁMARA, M.; REGLERO, G.; TABEA, J. Differences among Spanish and Latin-American banana cultivars: morphological, chemical and sensory characteristics. Food Chemistry, London, n.59, p.411-419, 1997.

CORRÊA, M. O. G.; PINTO, D. D.; ONO, E. O. Análise da atividade respiratória em frutos de jabuticabeira. Revista Brasileira de Biociências, Porto Alegre,v.5, n.2., p.831-833, 2007.

COSETENG, M. Y.; LEE, C. Y. Changes in apple polyphenoloxidase and polyphenol concentrations in relation to degree of browning. Journal of Food Science, New York, v.52, n.4, p.985-989, 1987.

DONADIO, L. C. Jabuticaba (Myrciaria jaboticaba (Vell. Berg). Jaboticabal: FUNEP, 2000. 55p.

DURIGAN, J.F. Panorama do processamento mínimo de frutas. In: ENCONTRO NACIONAL SOBRE PROCESSAMENTO MÍNIMO DE FRUTAS E HORTALIÇAS, 3., 2004, Viçosa. Anais... p. 9-12.

EREL, O. A novel automated direct measurement method for total antioxidant capacity using a new generation, more stable ABTS radical cation. Clinical Biochemical, Montreal, v.37, p.277-285, 2004.

FINGER, F. L.; VIEIRA, G. Controle da perda póscolheita de água em produtos hortícolas. Viçosa: UFV, 2002. 29 p.

FONSECA, M. J. O.; CENCI, S. A.; LEAL, N. R.; BOTREL, N. Uso de atmosfera modificada para conservação pós-colheita do mamão "Golden". Revista Brasiliera de Fruticultura, Jaboticabal, v.25, n.3, p.537-539, 2003.

HUANG, D.; OU, B.; HAMPSCH-WOODILL, M. F.; JUDITH, A.; PRIOR, R. L. Highthroughput assay of oxygen radical absorbance capacity (ORAC) using a multichannel liquid handling system coupled with a microplate fluorescence reader in 96-well format. Journal of Agricultural Food Chemistry, Easton, v.50, p.4437-4444, 2002.

JACOBO-VELÁZQUEZ, D. A.; CISNEROSZEVALLOS, L. Correlations of antioxidant activity versus phenolic content revisited: A new approach in data analysis for food and medicinal plants. Journal of Food Science, New York,v.74 n.9, p. R107 - R113, 2009.
MACHADO, N.C.; COUTINHO, E.F.; CAETANO, E.R. Embalagens Plásticas e refrigeração na conservação pós-colheita de jabuticabas. Revista Brasileira de Fruticultura, Jaboticabal, v. 29, n. 1, p. 166-168, 2007

MAGALHÃES, M. M.; BARROS, R. S.; FINGER, F. L. Changes in structural carbohydrates in developing fruit of Myrciaria jaboticaba. Scentia Horticulturae, Amsterdam, v. 66, p. 17-22, 1996.

MARTINS, C. R.; CANTILLANO, R. F. F.; FARIAS, R. de M.; ROMBALDI, C. V. Atividade polifenoloxidase em pós-colheita de pêssegos de pomares de produção integrada e convencional. Ciência Rural, Santa Maria, v. 34, n.3, p.749-754, 2004.

MARTINS, R. N.; DIAS, M. S. C.; VILLAS BOAS, E. V. de B.; SANTOS, L. O. Armazenamento refrigerado de banana 'Prata-Anã' proveniente de cachos com 16; 18 e 20 semanas. Ciência Agrotecnica, Lavras, v.31, n.5, p. 1423-1429, 2007.

McCREADY, P.M.; McCOMB, E.A. Extraction and determination of total pectic material. Analytical Chemistry, Washington, v. 24, n.12, p.1586-1588, 1952.

NEVES, L. C.; SILVA, V. X. DA; BENEDETTE, R. M.; SOUZA PRILL, M. A. DE; VIEITES, R. L.; ROBERTO, S. R. Conservação de uvas "Crimson Seedless" e "Itália", submetidas a diferentes tipos de embalagens e dióxido de enxofre $\left(\mathrm{SO}_{2}\right)$. Revista Brasileira de Fruticultura, Jaboticabal, , v.30, n.1, p. $65-73,2008 b$.

NEVES, L. C.; BENEDETTE, R. M.; SILVA, V. X da; VIEITES, R. L.; ROBERTO, S. R. Dano de frio em limas-ácidas, colhidas em diferentes épocas e submetidas a tratamentos térmicos e bioquímicos. Revista Brasileira de Fruticultura, Jaboticabal, v.30, n.2, p.337-384, 2008a.

NEVES, L. C.; BENEDETTE, R. M.; SILVA.; V. X.; LUCHETTA, L.; ZANUZZO, M. R.; ROMBALDI, C. V. Comportamento pós-colheita de caquis cv. Fuyu, através da atmosfera modificada passiva e da adsorção de etileno armazenados sob refrigeração. Revista Brasileira de Fruticultura, Jaboticabal, v.28, n.3, p.431-434, 2006. 
OU, B.; HAMPSCH-WOODILL, M.; PRIOR, R. L. Development and validation of an improved oxygen radical absorbance capacity assay using fluorescein as the fluorescent probe. Journal of Agricultural and Food Chemistry, Easton, v.49, p.4619-4926, 2001.

PECH, J. C. Unravelling the mechanisms of fruit ripening and development of sensory quality thought the manipulation of ethylene biosynthesis in melon. In: NATOADVANCED RESEARCH WORSHOPON BIOLOGY AND BIOTECHNOLOGYOF THE PLANT HORMONE ETHYLENE, 2002, Murcia. Anais...

PRIOR, R.L.; HOANG, H. A.; GU, L.; WU, X.; BACCHIOCCA, M.; HOWARD , L.; HAMPSCHWOODILL, M.; HUANG, D.; OU, B.; JACOB, R. Assays for hydrophilic and lipophilic antioxidant capacity (oxygen radical absorbance capacity (ORAC)) of plasma and other biological samples. Journal of Agricultural and Food Chemistry, Easton, v.51, p. 3273-3279, 2003.

ROBARDS, K.; PRENZLER, P. D.; TUCKER, G.; SWATSITANG, P.; GLOVER, W. Phenolic compounds and their role in oxidative processes in fruits. Food Chemistry, London, v.66, p. 401-436, 1999.
SILVA, B. M.; ANDRADE, P. B.; VALENTAO, P.; FERRERES, F.; SEBRA, R. M.; FERREIRA, M. Quince (Cydonia oblonga Miller) fruit (pulp, peel, and seed) and jam: Antioxidant activity. Journal of Agricultural and Food Chemistry, Easton, n.52, p.4705-4712. 2004

SINGLETON, V. L.; ORTHOFER, R.; LAMUELA, R. M. Analysis of totalphenols and other oxidation substrates and antioxidants by means of FolinCiocalteau reagent. Methods of Enzymology, San Diego, v.299, p. 152-178, 1999.

YEH, C. T.; YEN, G. C. Induction of apoptosis by the anthocyanidins through regulation of $\mathrm{Bcl}-2$ gene and activation of c-jun n-terminal kinase cascade in hepatoma cells. Journal of Agricultural and Food Chemistry, Easton, v.53, p.1740-1749, 2005.

ZENEBON, O.; PASCUET, N.S.; TIGLEA, P. (Coord.). Métodos físico-químicos para análise de alimentos. São Paulo: Instituto Adolfo Lutz, 2008. p. 1020 . 